\title{
O PROTOCOLO AGROAMBIENTAL E SUA INFLUÊNCIA NA GESTÃO AMBIENTAL EMPRESARIAL: UM ESTUDO DE MÚLTIPLOS CASOS EM AGROINDÚSTRIAS E FORNECEDORES DE CANA-DE-AÇÚCAR DA MICRORREGIÃO DE ASSIS (SP)
}

Edenis Cesar de Oliveira*

Raquel da Silva Pereira**

RESUMO: Estudos têm evidenciado que a inserção da dimensão ambiental na gestão corporativa pode trazer ganhos de competitividade para as organizações, além de melhorar sua imagem diante de seus stakebolders. A demanda social por um ambiente mais limpo, aliada ao aumento da regulação ambiental, tem forçado as empresas do setor sucroenergético a implementarem programas extensivos de prevenção e mitigação dos impactos ambientais. Dessa concepção, surge o Protocolo Agroambiental do Setor Sucroenergético Paulista, que consiste em um acordo de cooperação assinado em junho de 2007 entre o governo do Estado de São Paulo, representado pelas Secretarias de Estado do Meio Ambiente e da Agricultura e Abastecimento, a União da Indústria de Cana-de-Açúcar e a Organização de Plantadores de Cana da Região Centro-Sul. A pesquisa aqui apresentada objetivou apurar a percepção dos gestores das agroindústrias e fornecedores signatários, situados na Microrregião de Assis (SP), sobre a influência do Protocolo Agroambiental no processo de gestão ambiental empresarial. Foram aplicadas dezenove entrevistas semiestruturadas com os gestores ambientais de cada organização signatária. Utilizou-se a análise de conteúdo, com apoio do software Atlas.ti. 7. Os resultados evidenciaram forte influência do Protocolo Agroambiental nos processos de gestão ambiental das organizações, sobretudo com a implementação e execução de ações para atender as diretivas técnicas do Protocolo Agroambiental.

PALAVRAS-CHAVE: Desenvolvimento sustentável; Gestão ambiental; Meio ambiente; Protocolo agroambiental; Setor sucroenergético.

\section{AGRO-ENVIRONMENTAL PROTOCOL AND ITS INFLUENCE ON ENTREPRENEURS' ENVIRONMENTAL MANAGEMENT: A STUDY ON MULTIPLE CASES OF AGROINDUSTRIES AND SUGARCANE SUPPLIERS IN THE MICRO-REGION OF ASSIS, BRAZIL}

Doutor em Administração pela PPGA-USCS; Docente Adjunto da Universidade Federal de São Carlos (UFSCar), Campus Lagoa do Sino, Brasil; E-mail de correspondência: edeniscesar@ufscar.br

** Universidade Municipal de São Caetano do Sul (USCS), Brasil. 
ABSTRACT: Several studies have shown that the introduction of the environmental dimension in corporative management may provide competition stances for companies and improve their image for stakeholders. Social demands for a cleaner environment coupled to an increase in environmental regulations have made companies of the sugar-fuel sector to implement extensive programs for the prevention and mitigation of environmental impacts. The Agro-Environmental Protocol of the Sugar-fuel sector of the state of São Paulo is a cooperation agreement signed in June 2007 between the government of the state of São Paulo, represented by the Departments for the Environment and Agriculture and Supply, Sugarcane Industries and the Organization of Sugarcane Farmers of the Center-South Region. Current research assessed the perception of agro-industrial managers and suppliers in the Assis Micro-region on the effects of the Agro-environmental Protocol within the process of environmental management. Nineteen half-structured interviews were undertaken with environmental managers of each organization. Content analysis with Atlas.ti. 7 was employed. Results show a strong influence of the Agro-Environmental protocol in the process of environmental management of the companies, especially the establishment and execution of actions to attend to the technical directions of the Agro-Environmental Protocol.

KEY WORDS: Sustainable Development; Environmental Management; Environment; Agro-Environmental Protocol; Sugar-fuel Segment.

\section{INTRODUÇÃO}

Vive-se atualmente uma crise ambiental sem precedentes na história da humanidade, caracterizada, sobretudo por mudanças climáticas, aumento da poluição e escassez de recursos naturais.

De acordo com Leff (2006), a degradação do meio ambiente e a crise energética, entre outras, foram evidenciadas nas últimas décadas do século XX como uma crise de civilização, questionando a racionalidade econômica e tecnológica dominantes.

A problemática ambiental gerou mudanças globais em sistemas socioambientais de alta complexidade, afetando as condições de sustentabilidade do planeta como um todo, implicando diretamente na necessidade de internalizar as bases ecológicas, bem como os princípios jurídicos e sociais no intuito de 
salvaguardar a gestão democrática dos recursos naturais.

O crescente interesse pelas questões ambientais no âmbito da sociedade contemporânea é reflexo direto da degradação ambiental provocada pelo sistema produtivo como resultado das cobranças e articulações das mais diversas esferas sociais com o fito de propor uma mudança paradigmática no binômio homemnatureza.

No cerne dessa questão tem-se o polêmico debate entre desenvolvimento e meio ambiente que, de certo modo, já encontrou refúgio na proposta do desenvolvimento sustentável, "aquele que atende às necessidades do presente sem comprometer a possibilidade de as gerações futuras atenderem a suas próprias necessidades" (CNMAD, 1988, p. 46).

Importa frisar que a questão sobre meio ambiente e desenvolvimento é interdisciplinar, envolvendo aspectos tecnológicos, ecológicos, sociais, políticos e éticos, devendo os decisores públicos desenvolver políticas que provejam orientação e regulamentação às partes interessadas (BOOTSMA et al., 2014; ZHEN et al., 2014).

A interdisciplinaridade utiliza os desafios da vida real como gênese. Assim, lidar com a complexidade do desenvolvimento sustentável requer colaboração de vários atores (academia, organizações empresariais, governo e sociedade civil). Parte-se do pressuposto de que não existe uma única disciplina, perspectiva ou abordagem que ofereça respostas completas e satisfatórias aos desafios da sustentabilidade. Portanto, faz-se necessária uma busca interativa para soluções colaborativas (SHRIVASTAVA et al., 2013; SCHALTEGGER et al., 2013).

A sustentabilidade desafia os tomadores de decisão não apenas a gerir os recursos em um dado momento, mas gerenciá-los ao longo do tempo, considerando as incertezas, uma vez que o futuro nem sempre é conhecível (BANSAL; DESJARDINE, 2014). Nesse sentido, líderes empresariais têm sido levados a considerar seriamente o impacto das atividades sobre o meio ambiente da empresa (TIJANI, 2015).

Em conformidade com suas características e as especificidades do meio no qual estão diretamente inseridas, as organizações estão submetidas a diferentes tipos e intensidades de pressão. Assim, a empresa pode corresponder de várias formas a este ambiente de pressão, variando de uma postura de indiferença até um posicionamento estratégico (ABREU et al., 2013). Além disso, considerando que a 
reputação da empresa constitui-se em uma vantagem competitiva, uma das fontes de reputação refere-se à maneira como a organização incorpora as questões ambientais (MILES; COVIN, 2000).

Assim, as empresas passaram a incorporar a dimensão ambiental na gestão dos seus negócios. A solução dos problemas ambientais, ou sua minimização, exige das empresas uma postura diferenciada que, impreterivelmente, deve considerá-los em suas decisões estratégicas (BARBIERI, 2007).

De acordo com Backer (2002), da integração entre negócios e meio ambiente surge a gestão ambiental empresarial como possibilidade de a organização abrigar processos que reduzam os impactos ambientais causados por suas atividades.

Gestão ambiental diz respeito à incorporação de objetivos e estratégias ambientais aos objetivos e estratégias mais amplos existentes na organização (HADEN et al., 2009), afinal, os conceitos de preservação ambiental e gestão estão intrinsicamente conectados, sendo, ambos, parte do mundo dos negócios (PSOMAS et al., 2011).

González-Benito e González-Benito (2006) substanciam que o principal fator que leva as organizações a adotarem a gestão ambiental refere-se às exigências dos stakebolders. De fato, a pressão das partes interessadas tem sido significativamente apontada como um importante fator para elevar o nível de transparência das empresas a partir da divulgação de seus relatórios socioambientais (FERNANDEZFEIJOO et al., 2014; TATOGLU et al., 2015).

A melhoria do desempenho ambiental representa uma fonte potencial de vantagem competitiva, aumentando a eficiência dos processos, melhoria da produtividade, além da redução de custos e novas oportunidades de mercado (ALEXOPOULOS et al., 2012).

Os resultados do trabalho de Gotschol et al. (2014) proporcionam sustentação à opinião predominante entre os pesquisadores quanto ao impacto positivo da performance ambiental da empresa sobre seu desempenho econômico.

Não obstante a isso, as empresas desempenham um papel crucial no processo de desenvolvimento econômico, sendo também responsáveis pela acentuada exploração de recursos naturais (KUDLAK, 2014). Por outro lado, constituem-se em importantes players que precisam redesenhar suas estratégias, operações e atitudes 
com relação ao ambiente natural para contribuir com o equilíbrio e o equilíbrio do ecossistema global.

A gestão ambiental tem se tornado uma área de importância fundamental para o estabelecimento de novos paradigmas da concorrência empresarial e, portanto, tem surdido como um espaço de investigação e prática de negócios na última década (DAO et al., 2011; ALBINO et al., 2012), em especial para o setor sucroenergético.

Nesse contexto, sobressai o papel da Secretaria de Estado do Meio Ambiente (SMA) e da Secretaria de Agricultura e Abastecimento (SAA), ao estabelecerem parceria com o setor sucroenergético paulista, por meio da União da Indústria de Cana-de-Açúcar (UNICA) e da Organização de Plantadores de Cana da Região CentroSul do Brasil (ORPLANA), cuja finalidade é desenvolver tratativas que resultem em ações a serem executadas pelas agroindústrias e fornecedores do setor.

A referida parceria resultou na elaboração de um Acordo de Cooperação, o Protocolo Agroambiental, programa integrante do Projeto Etanol Verde, considerado um projeto estratégico da Secretaria do Meio Ambiente do Estado de São Paulo, cujo objetivo precípuo consiste em estabelecer diretivas que promovam ações que, por sua vez, estimulem a sustentabilidade da cadeia produtiva do açúcar, etanol e bioenergia.

Face ao exposto, a questão de pesquisa que impulsiona a realização desse estudo pode ser definida da seguinte maneira: Qual a influência do Protocolo Agroambiental do ponto de vista dos gestores das agroindústrias e fornecedores do setor sucroenergético da Microrregião de Assis (SP) no processo de gestão ambiental de suas respectivas empresas? O objetivo desta pesquisa consiste em apurar a influência do Protocolo Agroambiental no processo de gestão ambiental empresarial, a partir das percepções dos gestores das agroindústrias e fornecedores da Microrregião de Assis (SP).

Para atender à questão proposta, foram estudadas quatro agroindústrias produtoras de açúcar, álcool e/ou bioenergia e dois fornecedores de cana-de-açúcar, todos localizados na microrregião geográfica de Assis (SP), distribuídas em sete municípios. 


\subsection{BREVE CARACTERIZAÇÃO DA ÁREA DE ESTUDO}

Para fins desse estudo foi considerada a concepção clássica de microrregião, entendida como um agrupamento de municípios limítrofes que exigem planejamento integrado para o seu desenvolvimento e integração regional, que apresente, cumulativamente, características de integração funcional de natureza físico-territorial, econômico-social e administrativa (SÃO PAULO, 1994).

De acordo com Graymore et al. (2008), a região tem emergido como um foco substancial para pesquisadores, gestores de sustentabilidade dos recursos naturais, além dos técnicos envolvidos com o planejamento estratégico que visa desenvolver e implementar metas monitoráveis.

A Microrregião de Assis é uma das microrregiões do Estado de São Paulo pertencente à mesorregião de Assis, cuja população, em 2014, foi estimada em 278.220 habitantes, dividida em 17 municípios (IBGE, 2014). A Microrregião assume características de uma microrregião com polo na cidade de Assis. Trata-se de um espaço geográfico que se qualifica por uma forte integração comercial entre os municípios que compõem o território em questão. Possui a potencialidade de um polo modal de transportes, que sobressai com a expansão das atividades econômicas no interior do Estado de São Paulo (OLIVEIRA et al., 2014).

Há predominância de municípios com população pequena, característica típica da maioria das cidades do interior do Estado. Entretanto, são municípios que possuem grande área territorial, o que favorece a produção agropecuária e, especialmente, a produção canavieira.

As agroindústrias, os fornecedores e a associação previamente selecionados para esta pesquisa estão localizados nos municípios de Assis, Paraguaçu Paulista, Maracaí, Tarumã, Quatá e Borá.

\section{REVISÃO BIBLIOGRÁFICA}

\subsection{O PROTOCOLO AGROAMBIENTAL}

A demanda social por um ambiente mais limpo, aliada ao aumento da regulação ambiental, tem forçado as empresas a promoverem efetivamente 
programas de redução de seus impactos ambientais, prevenindo a poluição, além de envidarem esforços para se anteciparem às novas demandas (ação proativa).

A proposta do Protocolo Agroambiental consistiu em uma alternativa para reduzir os prazos determinados pela Lei Estadual 11.241/2002 que trata do fim da colheita da cana com o uso do fogo. Tal propositura caracterizou uma mudança na postura do setor público que, ao invés de trabalhar com o princípio de comando-econtrole, passa a adotar o sistema de parceria com o setor canavieiro, possibilitando seu engajamento na temática ambiental (SMA, 2008).

$\mathrm{Na}$ perspectiva de Herrera (2014), o Protocolo Agroambiental vai além da redução e supressão das queimadas, dispondo sobre outros temas de extrema relevância, como a proteção dos remanescentes florestais de nascentes e matas ciliares, o controle das erosões e melhores práticas de manejo do solo, o adequado gerenciamento das embalagens dos produtos fitossanitários, além da redução do consumo de água no processo industrial. Estudos desenvolvidos nessa mesma região demonstraram aumento de áreas verdes, redução significativa da queima da canade-açúcar e redução do consumo de água ( $\mathrm{m}^{3} /$ ton. de cana processada), inferior à média do Estado (OLIVEIRA; PEREIRA, 2013).

O Protocolo Agroambiental define diretivas técnicas ambientais a serem implementadas e executadas pelas agroindústrias signatárias. O Quadro 1 demonstra as diretivas técnicas do Protocolo Agroambiental para as unidades agroindustriais.

Quadro 1. Diretivas Técnicas do Protocolo Agroambiental para as unidades agroindustriais

(continua)

\begin{tabular}{|c|l|}
\hline DIRETIVAS & \multicolumn{1}{c|}{ CONTEÚDO DESCRITIVO } \\
\hline A & $\begin{array}{l}\text { Antecipar, nos terrenos com declividade até 12\%, o prazo final para eliminação da } \\
\text { queimada da cana-de-açúcar, de 2021 para 2014, adiantando o percentual de cana } \\
\text { não queimada, em 2010, de 10\% para 30\%. }\end{array}$ \\
\hline B & $\begin{array}{l}\text { Antecipar, nos terrenos com declividade acima de 12\%, o prazo final para } \\
\text { eliminação da queimada de cana-de-açúcar, de 2031 para 2017, adiantando o } \\
\text { percentual de cana não queimada, de 10\% para 30\%. }\end{array}$ \\
\hline C & $\begin{array}{l}\text { Não utilizar a prática da queima da cana-de-açúcar para fins de colheita nas áreas } \\
\text { de expansão de canaviais. }\end{array}$ \\
\hline
\end{tabular}


(conclusão)

\begin{tabular}{|c|l|}
\hline DIRETIVAS & \multicolumn{1}{c|}{ CONTEÚDO DESCRITIVO } \\
\hline D & $\begin{array}{l}\text { Adotar ações para que não ocorra a queima a céu aberto, do bagaço de cana, ou } \\
\text { de qualquer outro subproduto da cana-de-açúcar. }\end{array}$ \\
\hline E & $\begin{array}{l}\text { Proteger as áreas de mata ciliar das propriedades canavieiras, devido à relevância } \\
\text { de sua contribuição para a preservação ambiental e proteção à biodiversidade. }\end{array}$ \\
\hline F & $\begin{array}{l}\text { Proteger as nascentes de água das áreas rurais do empreendimento canavieiro, } \\
\text { recuperando a vegetação ao seu redor. }\end{array}$ \\
\hline G & $\begin{array}{l}\text { Implementar Plano Técnico de Conservação do Solo, incluindo o combate à } \\
\text { erosão e a contenção de águas pluviais nas estradas internas e carreadores. }\end{array}$ \\
\hline H & $\begin{array}{l}\text { Implementar Plano Técnico de Conservação de Recursos Hídricos, favorecendo } \\
\text { uso adequado do ciclo hidrológico, incluindo programa de controle da qualidade } \\
\text { da água e reuso da água utilizada no processo industrial. }\end{array}$ \\
\hline I & $\begin{array}{l}\text { Adotar boas práticas para descarte de embalagens vazias de agrotóxicos, } \\
\text { promovendo a tríplice lavagem, armazenamento correto, treinamento adequado } \\
\text { dos operadores e uso obrigatório de equipamentos de proteção individual. }\end{array}$ \\
\hline J & $\begin{array}{l}\text { Adotar boas práticas destinadas a minimizar a poluição atmosférica de processos } \\
\text { industriais e otimizar a reciclagem e o reuso adequados dos resíduos gerados na } \\
\text { produção de açúcar e etanol. }\end{array}$ \\
\hline
\end{tabular}

Fonte: SMA/Etanol Verde (2008).

Ressalta-se que muitas das diretivas são mais restritivas que a própria legislação ambiental aplicada no Estado de São Paulo, com destaque para os prazos para redução e total supressão do uso do fogo para colheita. Os fornecedores de cana-de-açúcar devem aderir ao Protocolo Agroambiental por meio de sua associação de classe.

\subsection{GESTÃO AMBIENTAL NO SETOR SUCROENERGÉTICO}

O setor sucroenergético apresenta grande potencial econômico, decorrente da comercialização de produtos e subprodutos do processamento da cana-de-açúcar, como o açúcar, o etanol e a bioenergia. 
A produção total de cana-de-açúcar moída na safra 2014/2015 é estimada em 642,1 milhões de toneladas, queda de $2,5 \%$ em relação ao volume colhido na safra 2013/2014, que foi de 658,8 milhões de toneladas. Na Região Centro-Sul a produção está estimada em 602,1 milhões de toneladas, o que representa 3,2\% a menos se comparado à safra anterior (CONAB, 2014). O Estado de São Paulo é o maior produtor de cana-de-açúcar do país (WELLS; FARO, 2011).

Machado e Cirani (2013) apontam que o Brasil acumulou liderança tecnológica do etanol como biocombustível a partir de uma trajetória lenta, cumulativa e gradual, com ganhos na produtividade, além dos ganhos logísticos das usinas, bem como do reaproveitamento dos subprodutos industriais.

Nos idos de 1970, a indústria sucroalcooleira apresentava elevado potencial poluidor (ROSSETTO, 2010), agravado pela escassa regulamentação e fiscalização do setor. Nas décadas seguintes, esse cenário começa a tomar uma nova configuração. Impulsionadas por pressões de partes interessadas, as indústrias passaram a se posicionar de maneira diferenciada com relação aos seus impactos ambientais, sobretudo ao incorporarem novas tecnologias que permitiram maior eficiência no seu desempenho ambiental (JABBOUR et al., 2015).

Cada setor possui suas próprias exigências a respeito dos impactos ambientais que devem ser constantemente monitorados, bem como a frequência e os limites permitidos, enquanto as exigências de modelagem e os interesses políticos são frequentemente gerais para todos os setores (GOLDSTEIN et al., 2011).

Apesar da tradição e importância na economia nacional, o setor canavieiro tem sido alvo de julgamentos críticos, mormente por ser considerado de elevado potencial poluidor. Rodrigues (2013) entende que, se, de fato, a expansão da cana afeta, direta ou indiretamente, outros setores, torna-se necessária uma análise mais acurada, no intuito de investigar os impactos, seja na esfera ambiental, social, econômica ou institucional.

O setor sucroenergético brasileiro apresenta uma crescente tendência no uso mais eficiente dos recursos, bem como a promoção de boas práticas de manejo que contribuem na redução dos impactos ambientais (GALDOS et al., 2013).

De maneira geral, o setor vem apresentando mudanças substanciais na gestão de suas atividades (agrícolas e industriais), adotando medidas com o fito de atenuar 
os efeitos deletérios ao meio ambiente. Esse é o pressuposto que se investigou nesse estudo, sob a ótica da percepção dos gestores diretamente envolvidos com as ações empreendidas pelas organizações signatárias, no cumprimento das diretivas técnicas do Protocolo Agroambiental.

\section{MATERIAIS E MÉTODOS}

Esta é uma pesquisa descritiva e exploratória considerando-se que, conforme aponta Gil (2010), elaborada com a finalidade de identificar possíveis relações entre variáveis. Em relação à sua natureza, esta pesquisa pode ser caracterizada como qualitativa (MYERS, 2009). Este tipo de pesquisa é adequada para a obtenção de uma visão crítica e reflexiva sobre o mundo das organizações e seus processos (ERIKSSON; KOVALAINEN, 2008).

Quanto aos métodos empregados para coleta de dados, utilizou-se inicialmente como delineamento a pesquisa bibliográfica e em dados disponíveis no site oficial da Secretaria de Estado do Meio Ambiente (SMA/Projeto Etanol Verde). Posteriormente, procedeu-se à elaboração de um roteiro semiestruturado que foi submetido à apreciação de quatro especialistas na área de gestão ambiental empresarial, os quais verificaram a pertinência da relação das questões com o arcabouço teórico do trabalho.

O roteiro serviu como eixo norteador para as entrevistas, cujo conteúdo foi digitalmente gravado e devidamente transcrito na íntegra, retornando, via e-mail, ao entrevistado para que desse endosso final ao conteúdo.

A técnica de análise de dados adotada neste estudo foi a Análise de Conteúdo, que consiste em um conjunto de instrumentos metodológicos em constante aperfeiçoamento, que se aplicam a discursos, falas, depoimentos, extremamente diversificados (BARDIN, 2011).

Para obter melhor acurácia das informações levantadas, utilizou-se o software ATLAS.ti 7, que consiste em uma ferramenta para análise de dados qualitativos, atribuindo maior visibilidade e transparência à análise de dados (WALTER; BACH, 2013). Segundo Cantero (2014), pesquisadores mais ortodoxos são relutantes no 
uso de software como ferramenta de auxílio no processo interpretativo, uma vez que o trabalho artesanal é a essência da análise qualitativa.

Todavia, entende-se que o uso da ferramenta serve de apoio e, em momento algum, substitui o esforço cognitivo necessário do pesquisador, notadamente na formulação das categorias de análise. Essa propositura encontra respaldo em Leite (2013) ao asseverar que o Atlas.ti apresenta uma interface coerente com essa técnica de análise, podendo auxiliar na organização, bem como no tratamento de um número elevado de informações.

\section{RESULTADOS E DISCUSSÃO}

\subsection{CARACTERIZAÇÃO DOS CASOS ESTUDADOS: UMA SÍNTESE}

O Quadro 2 apresenta, resumidamente, a caracterização histórica de cada um dos casos onde atuam os gestores que participaram da pesquisa.

Quadro 2. Síntese histórica dos casos onde atuam os gestores entrevistados

(continua)

\begin{tabular}{|l|l|}
\hline $\begin{array}{c}\text { CASOS DE } \\
\text { ESTUDO }\end{array}$ & \multicolumn{1}{c|}{ BREVE HISTÓRICO } \\
\hline AGR1 & $\begin{array}{l}\text { De origem familiar, é uma empresa 100\% nacional, fundada em 1980, com a } \\
\text { implantação do Proálcool. As atividades iniciaram com foco na produção de etanol } \\
\text { para o abastecimento regional, fornecendo, em 1983, mais de } 55 \text { mil m³ de etanol/ } \\
\text { ano. Em 1994 passou também a fabricar açúcar e, em 2002, acrescentou à sua atuação } \\
\text { a geração de energia elétrica, com o início da operação de sua Termoelétrica. }\end{array}$ \\
\hline \multirow{3}{*}{ AGR2 } & $\begin{array}{l}\text { O Grupo que congrega a AGR2, como atualmente constituído, teve início em 1935, } \\
\text { com a aquisição de uma usina no Vale do Paraíba, região Nordeste, comandado pelo } \\
\text { seu patriarca. Com o cultivo da cana-de-açúcar se transferindo para os tabuleiros } \\
\text { costeiros de Alagoas, o grupo instala sua segunda unidade em outro município da } \\
\text { mesma região, tendo isto ocorrido em 1970. Em 1976 com o advento do Proálcool } \\
\text { o grupo instala sua terceira unidade no município de Penedo. Em 2002 o grupo } \\
\text { adquire, no Estado de São Paulo, uma antiga usina, rebatizada de AGR2. A produção } \\
\text { comercial de açúcar e álcool foi iniciada em 2005. A AGR2 possui capacidade para } \\
\text { moer 7.000 toneladas de cana/dia e produz açúcares do tipo VHP e Cristal, além de } \\
\text { Álcool anidro e hidratado. }\end{array}$ \\
\hline
\end{tabular}


(conclusão)

\begin{tabular}{|c|c|}
\hline $\begin{array}{l}\text { CASOS DE } \\
\text { ESTUDO }\end{array}$ & BREVE HISTÓRICO \\
\hline AGR3 & $\begin{array}{l}\text { A AGR3 se destaca por ser uma empresa que compete em nível global. Possui política } \\
\text { de investimento em inovação, tecnologia e capacitação de colaboradores no intuito } \\
\text { de aumentar sua qualificação. Está atualmente entre as cinco maiores empresas } \\
\text { em faturamento e as três maiores distribuidoras de combustíveis do Brasil, sendo } \\
\text { a principal fabricante de etanol de cana-de-açúcar do país e a maior exportadora } \\
\text { individual de açúcar de cana no mercado internacional. }\end{array}$ \\
\hline AGR4 & $\begin{array}{l}\text { A AGR4 é uma multinacional brasileira especializada em produzir açúcar, etanol, } \\
\text { energia elétrica e ingredientes para alimentação humana e nutrição animal, por meio } \\
\text { da unidade de negócios acoplada à indústria. Trata-se de uma empresa com vocação } \\
\text { industrial, que processa a cana-de-açúcar e agrega valor aos produtos que dela podem } \\
\text { ser extraídos com tecnologia voltada para a inovação. Atua em setores importantes } \\
\text { para a economia brasileira e contribui para o crescimento do país ao empregar mais de } \\
3.700 \text { colaboradores, fomentar pesquisas em universidades nacionais e internacionais } \\
\text { e centros de inovação, comercializar energia elétrica gerada com uma fonte limpa e } \\
\text { renovável. }\end{array}$ \\
\hline FOR1 & $\begin{array}{l}\text { A FOR1 atua no setor de produção de cana-de-açúcar, laranja in natura e suco } \\
\text { concentrado de laranja. Nasceu da divisão dos ativos de um grupo maior, fundado } \\
\text { em } 1944 \text { e pioneiro na produção de cana no Vale do Paranapanema. São cerca de } 4,5 \\
\text { mil empregos diretos nas regiôes onde atua. }\end{array}$ \\
\hline FOR2 & $\begin{array}{l}\text { Com suas atividades concentradas no segmento agrícola de produção de cana-de- } \\
\text { açúcar, uma nova história começou a ser construída pelo Grupo que inclui a FOR2, } \\
\text { gerando cerca de } 2 \text { mil empregos diretos, com atuação nos Estados de São Paulo e } \\
\text { Mato Grosso do Sul, desde a reformulação de suas estratégias e diretrizes. A FOR2 } \\
\text { se tornou a principal fornecedora de cana-de-açúcar para a empresa AGR3. A FOR2 } \\
\text { expandiu suas atividades agrícolas para disponibilizar a sua matéria-prima e criou } \\
\text { um novo negócio em } 2011 \text { para a prestação de serviços de corte, carregamento e } \\
\text { transporte de cana-de-açúcar, a FOR2 Serviços, na busca por novos clientes para a sua } \\
\text { expansão no setor, aumentando o potencial energético das empresas envolvidas e } \\
\text { suprindo a necessidade dos parceiros. A FOR2 uniu informação, ação e resultados para } \\
\text { que houvesse uma evolução do trabalho no segmento, mantendo sua transparência } \\
\text { nas ações e garantindo sua credibilidade. A avaliaçãa, o aprimoramento, a projeção, a } \\
\text { inserção de novas tecnologias e a busca de soluçôes diárias continuam sendo os focos } \\
\text { da empresa, envolvendo o colaborador, a comunidade e o poder público. }\end{array}$ \\
\hline ASS1 & $\begin{array}{l}\text { A ASS1 foi fundada em 1977, a fim de organizar e representar a classe dos plantadores } \\
\text { de cana da região e prestar assistência social aos trabalhadores rurais canavieiros e } \\
\text { seus dependentes. O primeiro atendimento a um trabalhador rural ocorreu em } 1979 . \\
\text { O Departamento Agrícola da ASS1 iniciou suas atividades em 1983, com o advento da } \\
\text { implantação do Sistema de Pagamento de Cana pelo Teor de Sacarose, primeiramente } \\
\text { voltado ao acompanhamento das análises de cana nos laboratórios das usinas e } \\
\text { destilarias da região e posteriormente à prestação de assistência técnica integral ao } \\
\text { produtor de cana-de-açúcar. Desde então vem ampliando os serviços prestados aos } \\
\text { associados, orientando-os do planejamento de plantio até a colheita da cana. }\end{array}$ \\
\hline
\end{tabular}

Fonte: Dados da pesquisa (2014). 
Observa-se pelo resumo histórico que todas as empresas/instituição pesquisadas possuem entre 50 e 60 anos no mercado, o que, de certa forma, contribui para uma maior consolidação e menor suscetibilidade às mudanças $\mathrm{e}$ crises do mercado.

Em algumas organizações foi possível entrevistar mais de uma pessoa que estava ligada diretamente às questões ambientais da empresa.

A maioria dos gestores entrevistados confirmou ter dado mais ênfase às questões ambientais a partir da adesão ao Protocolo Agroambiental, o que pode ser constatado nos excertos transcritos das entrevistas realizadas com os técnicos. O Quadro 3 apresenta os entrevistados e seus respectivos cargos nas organizações.

Quadro 3. Quantidade de entrevistados por caso e respectivos cargos

(continua)

\begin{tabular}{|c|c|c|c|}
\hline $\begin{array}{l}\text { Casos } \\
\text { estudados }\end{array}$ & $\begin{array}{l}\text { Número de } \\
\text { Entrevistados }\end{array}$ & $\mathbf{N}^{\mathbf{o}}$ & Cargos \\
\hline \multirow{4}{*}{ AGR1 } & \multirow{4}{*}{04} & 1 & Técnico Ambiental \\
\hline & & 2 & Supervisor do Setor de Bem-Estar \\
\hline & & 3 & Supervisor de Plantio (Setor Agrícola) \\
\hline & & 4 & Diretor de Pessoas \\
\hline \multirow{3}{*}{ AGR2 } & \multirow{3}{*}{03} & 1 & Coordenadora Socioambiental \\
\hline & & 2 & Supervisor Agrícola \\
\hline & & 3 & Técnico em Química \\
\hline \multirow{3}{*}{ AGR3 } & \multirow{3}{*}{03} & 1 & Analista de Meio Ambiente \\
\hline & & 2 & Gerente Corporativo de Meio Ambiente \\
\hline & & 3 & Coordenador Administrativo \\
\hline AGR 4 & 01 & 1 & Analista de Preservação Ambiental \\
\hline \multirow{3}{*}{ FOR1 } & \multirow{3}{*}{03} & 1 & Gerente Agrícola \\
\hline & & 2 & $\begin{array}{l}\text { Técnico de Segurança do Trabalho e Meio } \\
\text { Ambiente }\end{array}$ \\
\hline & & 3 & Analista Ambiental \\
\hline
\end{tabular}


(conclusão)

\begin{tabular}{|c|c|c|c|}
\hline $\begin{array}{c}\text { Casos } \\
\text { estudados }\end{array}$ & $\begin{array}{l}\text { Número de } \\
\text { Entrevistados }\end{array}$ & No & Cargos \\
\hline \multirow{2}{*}{ FOR2 } & \multirow{2}{*}{02} & 1 & Supervisor de Planejamento Agronômico \\
\hline & & 2 & Supervisor de Controle e Custos Agrícolas \\
\hline \multirow{3}{*}{ ASS1 } & \multirow{3}{*}{03} & 1 & Presidente da Associação \\
\hline & & 2 & Gerente Agrícola \\
\hline & & 3 & Assistente Administrativo \\
\hline TOTAL & 19 & & \\
\hline
\end{tabular}

Fonte: Dados da pesquisa (2014).

Ao todo, foram ouvidos dezenove profissionais relacionados à área ambiental das empresas. Todavia, serão considerados nessa pesquisa somente os depoimentos mais relevantes e contundentes para o alcance do objetivo proposto. O Quadro 4 apresenta os excertos dessas entrevistas.

Quadro 4. Excertos das entrevistas sobre o Protocolo Agroambiental

\begin{tabular}{|c|c|c|}
\hline ¿্ৰ & 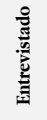 & Conteúdo - Fragmentos das Entrevistas \\
\hline \multirow{4}{*}{ 造 } & 1 & $\begin{array}{l}\text { [...] então desde } 2007 \text {, quando a gente aderiu ao Protocolo, a gente vem fazendo muita coisa } \\
\text { para mudar..... Tudo isso acho que veio amadurecendo com o Protocolo Agroambiental. }\end{array}$ \\
\hline & 2 & $\begin{array}{l}\text { A partir do Protocolo Agroambiental, e isso é fato, as empresas começaram a respeitar os } 30 \\
\text { e } 50 \text { metros das APPs; antigamente não, esperava-se a notificação da polícia florestal, do MP, } \\
\text { hoje é mais proativo. }\end{array}$ \\
\hline & 3 & $\begin{array}{l}\text { O Protocolo dá essa visualização no mercado; inclusive quando você vai fazer algum } \\
\text { empréstimo em banco, o Protocolo é exigido. Para gente renovar a licença do IBAMA, ele } \\
\text { (certificado) serve para mostrar que a gente é sustentável. As empresas estão ganhando muito } \\
\text { com o Protocolo, além do ganho ambiental, a questão da confiabilidade perante os órgãos } \\
\text { públicos. }\end{array}$ \\
\hline & 4 & $\begin{array}{l}\text { A AGR1 tá mudando bastante, mudando o foco na preservação ambiental, o que originou } \\
\text { mesmo a partir do Protocolo, antes do Protocolo as empresas faziam só o que a CETESB } \\
\text { exigia, naquele passo a passo, e aí o Protocolo exigiu prazos mais apertados. }\end{array}$ \\
\hline 录 & 1 & $\begin{array}{l}\text { O Novo Código Florestal reduziu de } 50 \text { metros para } 15 \text { metros a distância da mata ciliar, mas } \\
\text { nós temos seguido o Protocolo e mantido o distanciamento maior. }\end{array}$ \\
\hline
\end{tabular}


(continua)

\begin{tabular}{|c|c|c|}
\hline : & & Conteúdo - Fragmentos das Entrevistas \\
\hline \multirow{3}{*}{ 约 } & 1 & $\begin{array}{l}\text { O ganho que a agroindústria tem ao aderir ao Protocolo é essa questão mesmo do ganho } \\
\text { ambiental; você tem um cronograma para você se adequar para reduzir os seus impactos, } \\
\text { especialmente a queima da palha de cana; esse é o ganho direto, né! Há também o aspecto } \\
\text { da imagem da companhia." "[...] a partir da adesão ao Protocolo, a empresa elaborou um } \\
\text { plano de investimentos para cumprir as metas estabelecidas no Protocolo." "Se você não tem } \\
\text { o Protocolo é mais complicado você conseguir o licenciamento; com certeza o Protocolo } \\
\text { ajuda muito, facilita, porque muitas coisas o Protocolo já exige; então acho que a influência } \\
\text { foi positiva." "Principalmente nós que vendemos para Brasken, Coca-Cola, Nestlé, todas elas } \\
\text { pedem o Protocolo. Eles se interessam em olhar o Protocolo. Até para o Bonsucro }{ }^{1} \text {, eles } \\
\text { pedem o Protocolo. }\end{array}$ \\
\hline & 2 & $\begin{array}{l}\text { [...] foi muito bom essa questão do Protocolo Agroambiental porque trouxe mais próxima } \\
\text { uma questão que dava muitos problemas ambientais que é a questão das queimadas, a } \\
\text { redução da água... } \\
\text { Então, eu concordo com o Protocolo Agroambiental, até porque ele trouxe oportunidades } \\
\text { para a área de meio ambiente com alguns ganhos, inclusive transformar essa visão que até } \\
\text { tem uma questão sua aí no seu questionário de um custo para um valor. Hoje a área ambiental } \\
\text { subiu um degrau; ela tem que subir mais, mas ela já está num patamar de valor; então ele } \\
\text { trouxe uma visão para o usineiro de que o meio ambiente é um valor e não um custo. }\end{array}$ \\
\hline & 3 & $\begin{array}{l}{[\ldots] \text { o Protocolo Agroambiental pode ser considerado uma ferramenta de gestão para auxiliar }} \\
\text { o modo de gestão da empresa. }\end{array}$ \\
\hline 总 & 1 & $\begin{array}{l}\text { Desde que lançou o Protocolo Agroambiental, a AGR4 teve um esforço muito grande para } \\
\text { eliminar a queima da cana-de-açúcar; em } 2011 \text { nós conseguimos. } \\
\text { Então, o Protocolo Agroambiental, [...] trouxe um certo valor, ele ajudou a valorar essas ações, } \\
\text { as ações de redução de consumo de água, as ações de consumo energético, de proteção } \\
\text { às nascentes e matas ciliares; o Protocolo Agroambiental trouxe esse ganho. Realmente é o } \\
\text { que garante a sustentabilidade do nosso negócio. Nós temos treze (13) poços de captação } \\
\text { subterrânea, todos outorgados e uma captação de água superficial. Todos têm hidrômetro. } \\
\text { [...] o que a gente tem percebido de valor no Protocolo Agroambiental é quando a gente usa } \\
\text { ele, por exemplo, no atendimento a clientes, nas auditorias de sustentabilidade. Então, por } \\
\text { exemplo a Coca-Cola é cliente nosso, então ela valoriza mossa certificação pelo Protocolo } \\
\text { Agroambiental; a certificação Bonsucro, o Protocolo Agroambiental é muito útil; a primeira } \\
\text { certificação do nosso etanol para venda para os Estados Unidos, para o EPA o Protocolo } \\
\text { Agroambiental teve um peso importantíssimo. } \\
\text { [...] quando a gente implantou o Protocolo Agroambiental, além do ganho produtivo, nós } \\
\text { tivemos ganho na comunidade também; tivemos ganho em todas as etapas do processo } \\
\text { inclusive na comunidade. [...] o Protocolo Agroambiental é uma excelente ferramenta... }\end{array}$ \\
\hline
\end{tabular}

"Para maiores informações sobre a "certificação Bonsucro" ver OLIVEIRA, E. C.; PEREIRA, R. S.; GASPAR, M. A. Implementação de Certificação Ambiental Better Sugarcane Initiative - Bonsucro: Estudo de Caso de Empresa do Setor Sucroenergético. Revista Ibero-Americana de Ciências Ambientais, v. 4, n. 2, p. 24-45, 2013. DOI: 10.6008/ESS2179-6858.2013.002.0002. 
(conclusão)

\begin{tabular}{|c|c|c|}
\hline 总 & & Conteúdo - Fragmentos das Entrevistas \\
\hline 范 & 1 & $\begin{array}{l}\text { Quando surgiu o Protocolo, em 2008, } 2009 \text { a coisa começou a apertar, então } \\
\text { começamos a intensificar essas ações. }\end{array}$ \\
\hline ֻั: & 1 & $\begin{array}{l}{[. . .] \text { mas o Protocolo acelerou muita coisa aqui pra nós. A aquisição de maquinários, }} \\
\text { a mudança da mão de obra; então acho que desde } 2009 \text { por aí, as coisas vêm } \\
\text { mudando bastante. A gente já vem diminuindo bastante a colheita manual, as } \\
\text { queimadas, em } 2011 \text { e } 2012 \text { foram somente } 3 \%, 2013 \text { e } 2014 \text {, praticamente } 100 \% \text { da } \\
\text { colheita é mecanizada. } \\
\text { Antes do Protocolo não tinha essa preocupação. Então essa atitude de somente } \\
\text { arrendar área que tenha possibilidade de ser colhida mecanicamente começou a } \\
\text { partir do Protocolo. } \\
\text { [...] o Protocolo vem para nos agregar de maneira positiva tanto ambientalmente, } \\
\text { como para as próprias políticas da empresa, e para nós é bastante positivo, porque } \\
\text { o Protocolo, ele deu um incentivo muito grande à mecanização. } \\
\text { O monitoramento das emissóes atmosféricas foi graças ao Protocolo Agroambiental } \\
\text { que a gente começou a fazer o monitoramento nos veículos automotores; não era } \\
\text { uma prática que era feita aqui anteriormente. } \\
\text { [...] para nós é muito bem vista essa questão do Protocolo Agroambiental. } \\
\text { [...] desde quando o Protocolo Agroambiental foi implantado, nós temos essa } \\
\text { atribuição nesse setor quanto às questões ambientais. }\end{array}$ \\
\hline & 1 & $\begin{array}{l}\text { Com certeza, depois da adesão ao Protocolo houve uma mudança de mentalidade } \\
\text { dos produtores, uma preocupação em se adequar às exigências. }\end{array}$ \\
\hline 安 & 2 & $\begin{array}{l}\text { O Protocolo exige que se deixe, pelo menos } 30 \text { metros de espaço a partir do rio, } \\
\text { não exige que faça o reflorestamento, ele pode ocorrer naturalmente. Hoje, quando } \\
\text { você fala em mata ciliar pra eles (produtores), é tranquilo, já há essa consciência, } \\
\text { tem mais é que deixar mesmo, isso já não os preocupa. } \\
\text { Ele (o fornecedor) até pode optar por não aderir ao Protocolo, mas a gente mostra } \\
\text { pra ele a viabilidade, especialmente quando ele precisar de algo junto à CETESB, } \\
\text { porque, como eu falei pra você, quem tá no Protocolo tem certo privilégio... }\end{array}$ \\
\hline
\end{tabular}

Fonte: Dados da pesquisa (2014).

Nos depoimentos supra transcritos há evidências claras de que a adesão ao Protocolo, bem como o esforço de adaptação para atender às suas diretivas técnicas provocaram mudanças estratégicas no setor e, consequentemente, mudança no cenário ambiental, incluindo a flora e a fauna do cerrado interiorano do Estado.

O Protocolo Agroambiental, como certificação socioambiental, de caráter voluntário, pode ser considerado um instrumento de mercado, com o fito precípuo 
de promover mudanças e melhorias ambientais e sociais em setores produtivos da economia, a exemplo do setor sucroenergético.

Observa-se que o caso do gestor 1 da AGR2 ao afirmar "O Novo Código Florestal reduziu de 50 metros para 15 metros a distância da mata ciliar, mas nós temos seguido o Protocolo e mantido o distanciamento maior", corrobora a afirmação de que em vários pontos o Protocolo é mais restritivo que a própria legislação ambiental. Nessa mesma linha, é o caso do entrevistado 4 da AGR1, quando afirma que "A AGR1 tá mudando bastante, mudando o foco na preservação ambiental, o que originou mesmo a partir do Protocolo, antes do Protocolo as empresas faziam só o que a CETESB (Companhia Ambiental do Estado de São Paulo) exigia, naquele passo a passo, e aí o Protocolo exigiu prazos mais apertados".

Destaca-se, também, a fala do entrevistado 1 do FOR2 ao dizer que "o monitoramento das emissões atmosféricas foi graças ao Protocolo Agroambiental [...]; não era uma prática que era feita aqui anteriormente".

O Protocolo Agroambiental tem valido como um atestado de conformidade para certificações internacionais do setor o que pode ser constatado na fala do entrevistado $1 \mathrm{da}$ AGR4 ao afirmar que "[...] o que a gente tem percebido de valor no Protocolo Agroambiental é quando a gente usa ele, por exemplo, no atendimento a clientes, nas auditorias de sustentabilidade. [...] A Coca-Cola é cliente nosso, então, ela valoriza nossa certificação pelo Protocolo Agroambiental; a certificação Bonsucro, o Protocolo Agroambiental é muito útil; a primeira certificação do nosso etanol para venda para os Estados Unidos, para o EPA [United States Environmental Protection Agency] o Protocolo Agroambiental teve um peso importantíssimo".

A Figura 1 apresenta um gráfico gerado pelo ATLAS.ti., evidenciando a quantidade de citações em que apareceram a "Influência do Protocolo Agroambiental" após análise de conteúdo. 


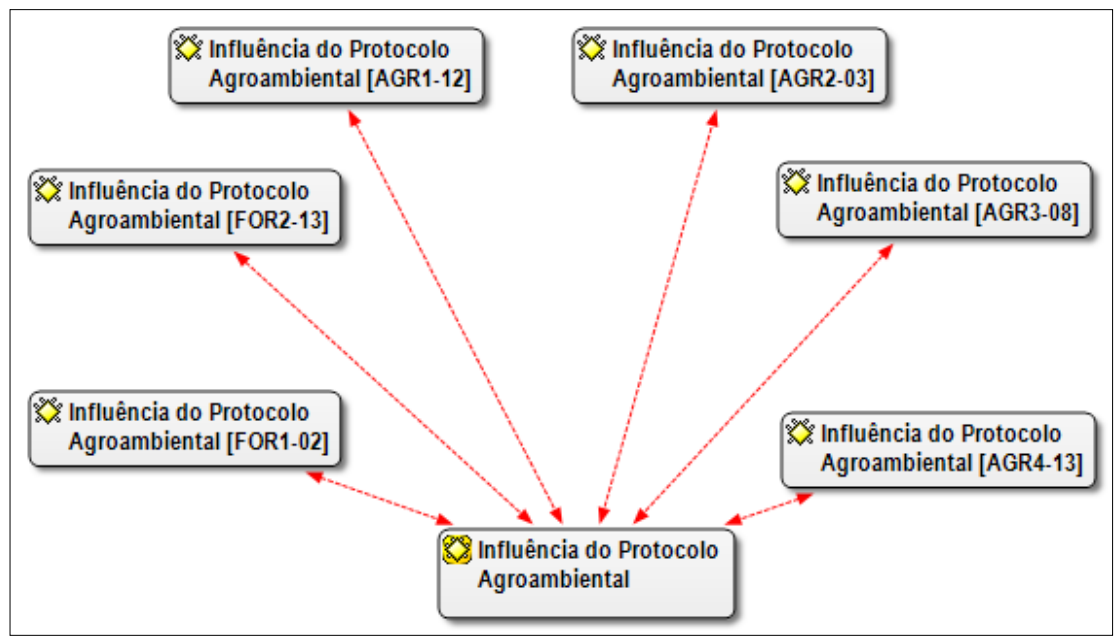

Figura 1. Número de citações sobre a "Influência do Protocolo Agroambiental" detectado em cada um dos casos estudados. Fonte: Dados da pesquisa (2014).

Dados oficiais do Protocolo Agroambiental mostram que o setor sucroenergético, neste caso composto pelos seus signatários (unidades agroindustriais e fornecedores de cana), agrega, sob responsabilidade de recuperação e proteção, 299.038 hectares de matas ciliares e mais de 9.300 nascentes.

Os resultados da safra 2013/2014 atestam que, desde a implantação do Protocolo Agroambiental, 7,17 milhões de hectares de cana deixaram de ser queimados, podendo-se afirmar que o equivalente a 4,4 milhões de toneladas de GEE (Gases de Efeito Estufa) deixaram de ser emitidos, além da não emissão de 26,7 milhões de toneladas de outros poluentes como Monóxido de Carbono, Hidrocarbonetos e Material Particulado (SMA, 2014).

No Estado de São Paulo, estudos têm mostrado que em locais em que o uso do solo foi destinado ao plantio da cana-de-açúcar, as áreas de mata aumentaram (RUDORFF et al., 2010), o que comprova o fato de que as agroindústrias e fornecedores de cana têm investido no reflorestamento das Áreas de Proteção Ambiental.

Tais resultados revelam que o sistema de parceria entre o setor público e o setor privado com objetivos bem definidos podem trazer resultados positivos a todos, notadamente, aos anseios sociais. Altera-se o paradigma do foco na vantagem competitiva para o foco na vantagem colaborativa (GLAVAS; MISH, 2015). 


\section{CONSIDERAÇÕES FINAIS}

Esta pesquisa objetivou apurar a influência do Protocolo Agroambiental no processo de gestão ambiental empresarial, a partir da percepção dos gestores ambientais das agroindústrias e fornecedores situados na Microrregião de Assis (SP).

Os resultados desse trabalho evidenciam a percepção de valor por parte dos gestores ambientais no que se refere ao Protocolo Agroambiental, que impulsionou mudanças positivas ocorridas em vários setores das empresas a fim de promover adequações para atender às diretivas técnicas do Protocolo.

Todavia, ressalta-se que o Protocolo Agroambiental é fruto de pressão social, que persuadiu o poder público e a iniciativa privada a darem resposta a essa demanda, o que vai ao encontro da assertiva proposta por vários autores de que $o$ principal fator que leva as organizações a adotarem a gestão ambiental diz respeito às exigências dos seus stakebolders (GONZÁLEZ-BENITO; GONZÁLEZ-BENITO, 2006; FERNANDEZ-FEIJOO et al., 2014; TATOGLU et al., 2015).

Além disso, o aumento da eficiência no desempenho ambiental representa uma potencial fonte de vantagem competitiva, com repercussão direta na melhoria dos processos, da produtividade, bem como redução de custos e geração de novas oportunidades de mercado (ALEXOPOULOS et al., 2012).

Outro ponto relevante diz respeito aos investimentos realizados em novas tecnologias (máquinas, equipamentos, sistemas de gestão, infraestrutura, entre outros) a fim de aumentar a eficiência dos processos tanto no campo (setor agrícola), quanto na indústria (produção).

Considera-se como limitações dessa pesquisa, o fato de ter sido utilizado somente um instrumento de coleta de dados (entrevista com roteiro semiestruturado), além do recorte geográfico, restrito à Microrregião de Assis (SP), muito embora seja uma região com expressiva tradição canavieira.

Sugere-se que, para trabalhos futuros, seja ampliada a área de abrangência, utilizando de outras ferramentas de coleta de dados, como o survey, por exemplo, para abarcar uma amostra representativa das agroindústrias e fornecedores signatários em todo o Estado de São Paulo. 


\section{REFERÊNCIAS}

ABREU, M. C. S.; CASTRO, F. C.; LAZARO, J. C. Avaliação da influência dos stakeholders na proatividade ambiental de empresas brasileiras. Revista de Contabilidade e Organizações, v. 17, p. 22-35, 2013.

ALBINO, V.; BALICE, A.; DANGEliCO, R. M.; IACOBOnE, F. A. The effect of the adoption of environmental strategies on green product development: a study of companies on world sustainability indices. International Journal of Management, v. 29, n. 2, p. 525-539, 2012.

ALEXOPOULOS, I.; KOUNETAS, K.; TZELEPIS, D. Environmental performance and technical efficiency, is there a link? The case of Greek listed firms. International Journal of Productivity and Performance Management, v. 61, n. 1, p. 6-23, 2012. DOI 10.1108/17410401211187480.

BACKER, P. Gestão ambiental: a administração verde. 2. ed. Rio de Janeiro: Qualitymark, 2002.

BANSAL, P.; DESJARDINE, M. R. Business sustainability: It is about time. Strategic Organization, v. 12, n. 1, p. 70-78, 2014. DOI: 10.1177/1476127013520265.

BARBIERI, J. C. Gestão ambiental: conceitos, modelos e instrumentos. 2. ed. São Paulo: Saraiva, 2007.

BARDIN, L. Análise de conteúdo. Lisboa: Edições 70, 2011.

BOOTSMA, M. C.; VERMEULEN, W. J. V.; van DIJK, J.; SCHOT, P. P. Added value and constraints of transdisciplinary case studies in environmental science curricula. Corporate Social Responsibility and Environmental Management, v. 21, n. 3, p. 155-166, 2014. DOI: 10.1002/csr.1314.

CANTERO, D. S. M. Teoría fundamentada y Atlas.ti: recursos metodológicos para la investigación educativa. Revista Electrónica de Investigación Educativa, v. 16, n. 1, p. 104-122, 2014. 
COMISSÃO MUNDIAL SOBRE O MEIO AMBIENTE E DESENVOLVIMENTO - CMMAD. Nosso futuro comum. Rio de Janeiro: Ed. FGV, 1988.

COMPANHIA NACIONAL DE ABASTECIMENTO - CONAB. Acompanhamento da safra brasileira: cana-de-açúcar, v. 1, n. 3, p. 1-27 - Safra 2014/2015 - Terceiro Levantamento, Dezembro/2014. Companhia Nacional de Abastecimento - Brasília: Conab, 2014. Disponível em: < http://www.conab.gov.br>. Acesso em: 23 dez. 2014.

DAO, V.; LANGELLA, I.; CARBO, J. From green to sustainability: Information Technology and an integrated sustainability framework. Journal of Strategic Information Systems, v. 20, n. 1, p. 63-79, 2011. DOI:10.1016/j.jsis.2011.01.002.

ERIKSSON, P.; KOVALAINEN, A. Qualitative Methods in Business Research. London: Sage, 2008.

FERNANDEZ-FEIJOO, B.; ROMERO, S.; RUIZ, S. Effect of stakeholders' pressure on transparency of sustainability reports within the GRI framework. Journal of Business Ethics, v. 122, n. 1, p. 53-63, 2014. DOI 10.1007/s10551-013-1748-5.

GALDOS, M.; CAVALETT, O.; SEABRA, J. E. A.; NOGUEIRA, L. A. H.; BONOMI, A. Trends in global warming and human health impacts related to Brazilian sugarcane ethanol production considering black carbon emissions. Applied Energy, v. 104, p. 576-582, 2013. DOI:10.1016/j.apenergy.2012.11.002.

GIL, A. C. Como elaborar projetos de pesquisa. 5. ed. São Paulo: Atlas, 2010.

GLAVAS, A.; MISH, J. Resources and capabilities of Triple Bottom Line firms: Going over old or breaking new ground? Journal of Business Ethics, v. 127, n. 1, p. 623642, 2015. DOI 10.1007/s10551-014-2067-1.

GOLDSTEIN, D.; HILLIARD, R.; PARKER, V. Environmental performance and practice across sectors: methodology and preliminary results. Journal of Cleaner Production, v. 19, p. 946-957, 2011. DOI:10.1016/j.jclepro.2010.12.012. 
GONZÁLEZ-BENITO, J.; GONZÁLEZ-BENITO, O. A review of de determinant factors of environmental proactivity. Business Strategy and the Environment, v. 15, n. 2, 2006. DOI: $10.1002 /$ bse. 450 .

GOTSCHOL, A.; DE GIOVANNI, P.; VINZI, V. E. Is environmental management an economically sustainable business? Journal of Environmental Management, v. 144, p. 73-82, 2014. DOI.org/10.1016/j.jenvman.2014.05.001.

GRAYMORE, M. L. M.; SIPE, N. G.; RICKSON, R. E. Regional sustainability: how useful are current tools of sustainability assessment at the regional scale? Ecological Economics, v. 67, p. 362-372, 2008. DOI:10.1016/j.ecolecon.2008.06.002.

HADEN, S. S. P.; OYLER, J. D.; HUMPHREYS, J. H. Historical, practical, and theoretical perspectives on green management: An exploratory analysis. Management Decision, v. 47, n. 7, p. 1041-55, 2009. DOI.org/10.1108/00251740910978287.

HERRERA, S. Análise da governança global da sustentabilidade dos biocombustíveis e proposta para o etanol brasileiro. 2014. 205f. Tese (Doutorado) - Universidade Federal do Rio de Janeiro, Programa de Planejamento Energético, Rio de Janeiro, RJ.

INSTITUTO BRASILEIRO DE GEOGRAFIA E ESTATÍSTICA (IBGE). Estimativas populacionais para os municípios brasileiros em 01.07.2014. Disponível em: $<\mathrm{ftp}$ ://ftp.ibge.gov.br/Estimativas_de_Populacao/Estimativas_2014/estimativa_ dou_2014.pdf $>$. Acesso em: 18 mar. 2015.

JABBOUR, C. J. C.; JUGEND, D.; JABBOUR, A. L. B. S.; GUNASEKARAN, A.; LATAN, H. Green product development and performance of Brazilian firms: measuring the role of human and technical aspects. Journal of Cleaner Production, v. 87, p. 442-451, 2015. DOI.org/10.1016/j.jclepro.2014.09.036.

KUDLAK, R. Critical insights from the corporate environmentalism - competitiveness investigations. Management of Environmental Quality: An International Journal, v. 25, n. 2, p. 111-131, 2014. DOI 10.1108/MEQ-11-2012-0072. 
LEFF, E. Epistemologia ambiental. 4. ed. São Paulo: Cortez, 2006.

LEITE, Y. V. P. Teoria Adaptativa e Atlas.ti 7: uma Parceria para o Desenvolvimento de Framework de Empreendedorismo Internacional. In: ENANPAD, 37., 2013, Rio de Janeiro. Anais... Rio de Janeiro: Anpad, 2013.

MACHADO, L. H. M.; CIRANI, C. B. S. Incentivos à inovação de Empresas de Base Tecnológica no Sistema Agroindustrial Sucroenergético Brasileiro: uma análise exploratória. In: ENCONTRO DA ANPAD, 37., 2013. Anais... Rio de Janeiro, ANPAD, 2013.

MILES, M. P.; COVIN, J. G. Environmental marketing: a source of reputational, competitive and financial advantage. Journal of Business Ethics, v. 23, p. 299-311, 2000.

MYERS, M. D. Qualitative research in business \& management. Los Angeles: Sage Publications, 2009.

OLIVEIRA, E. C.; GASPAR, M. A.; FERNANDES, J. L. N.; SILVA FILHO, J. R. T. Análise de um aglomerado no setor sucroenergético: Estudo de caso na microrregião geográfica de Assis-SP. Revista Brasileira de Administração Científica, v. 5, n. 3, 2014. DOI. org/10.6008\%2FSustenere2179-684X.2014.003.0008.

OLIVEIRA, E. C.; PEREIRA, R. S. Projeto Etanol Verde: o protocolo agroambiental e o compromisso com o meio ambiente no setor sucroenergético da microrregião de Assis (SP). In: SEMEAD - SEMINÁRIOS EM ADMINISTRAÇÃO, 16., 2013, São Paulo. Anais... São Paulo-SP: [s.n.], 2013.

PSOMAS, E. L.; FOTOPOULOS, C. V.; KAFETZOPOULOS, D. P. Motives, difficulties and benefits in implementing the ISO 14001 Environmental Management System. Management of Environmental Quality, n. 4, v. 22, p. 502-521, 2011.

RODRIGUES, D. M. T. Sustentabilidade do setor sucroalcooleiro na Microrregião de Ceres - GO. 2013. 281f. Tese (Doutorado em Ciências Ambientais) - Universidade Federal de Goiás, Programa de Doutorado em Ciências Ambientais, Goiânia, GO. 
ROSSETTO, R. A cana de açúcar e a questão ambiental. In: DINARDO-MIRANDA, L. L.; VASCONCELOS, A. C. M.; LANDELL, M. G. A. (Ed.). Cana de açúcar. Campinas: Instituto Agronômico (IAC), 2010.

RUDORFF, B. F. T.; AGUIAR, D. A.; SILVA, W. F.; SUGAWARA, L. M.; ADAMI, M.; MOREIRA, M. A. Studies on the rapid expansion of sugarcane for ethanol production in São Paulo state (Brazil) using Landsat Data. Remote Sensing, v. 2, p. 1057-1076, 2010. DOI:10.3390/rs2041057.

SÃO PAULO (Estado). Lei Complementar $\mathrm{n}^{0} 760$, de $1^{\circ}$ de agosto de 1994. Estabelece Diretrizes para a Organização Regional do Estado de São Paulo. Diário Oficial do Estado, v. 104, n. 142, 1994.

SECRETARIA DE ESTADO DO MEIO AMBIENTE - SMA (ESTADO). Etanol Verde. Roteiro de Apresentação do Relatório Descritivo - 2008. São Paulo: SMA, 2008. Disponível em: <http://www.ambiente.sp.gov.br/etanolverde/files/2011/10/ inovacao_etanol.pdf $>$. Acesso em: 21 nov. 2013.

SECRETARIA DE ESTADO DO MEIO AMBIENTE - SMA (ESTADO). Etanol Verde: Resultados Safra 2013-2014. Disponível em: < http://www.ambiente.sp.gov.br/ etanolverde/files/2014/05/Resultados-safra-2013_2014-Etanol-Verde.pdf $>$. Acesso em: 10 dez. 2014.

SCHALTEGGER, S.; BECKMANN, M.; HANSEN, E. G. Transdisciplinarity in corporate sustainability: mapping the field. Business Strategy and the Environment, v. 22, n. 4, p. 219-229, 2013. DOI: 10.1002/bse.1772.

SHRIVASTAVA, P.; IVANAJ, S.; PERSSON, S. Transdisciplinary study of sustainable enterprise. Business Strategy and the Environment, v. 22, n. 4, p. 230-244, 2013. DOI: $10.1002 /$ bse. 1773 .

TATOGLU, E.; BAYRAKTAR, E.; ARDA, Ö. A. Adoption of Corporate Environmental Policies in Turkey. Journal of Cleaner Production, 2015. DOI: 10.1016/j. jclepro.2014.12.039. in Press. 
TIJANI, A. The environmental perspectives of Tunisian accounting system: a theoretical study and recommendations for improvement. Journal of Accounting and Auditing, v. 2015, 2015. Article ID 291309, DOI: 10.5171/2015.291309.

WALTER, S. A.; BACH, T. M. Adeus papel, marca-textos, tesoura e cola: inovando o processo de análise de conteúdo por meio do Atlas.ti. Administração: Ensino e Pesquisa, v. 16, n. 2, p. 275-308, 2015. DOI: 10.13058/raep.2015.v16n2.236.

WELLS, P.; FARO, T. Eco-efficiency, self-sufficiency and sustainability in transport: the limits for Brazilian sugarcane ethanol policy. Natural Resources Forum, v. 35, p. 21-31, 2011.

ZHEN, N.; FU, B.; LU, Y.; WANG, S. Poverty reduction, environmental protection and ecosystem services: a prospective theory for sustainable development. Chinese Geographical Science, v. 24, n. 1, p. 83-92, 2014. DOI: 10.1007/s11769-014-0658-5.

Recebido em: 06 de maio de 2015 Aceito em: 27 de janeiro de 2016 